\title{
Acid Sphingomyelinase Inhibition Prevents Hemolysis During Erythrocyte Storage
}

\author{
Richard S. Hoehn ${ }^{a}$ Peter L. Jernigana,b Alex L. Changa Michael J. Edwards ${ }^{a}$ \\ Charles C. Caldwella Erich Gulbins ${ }^{a, b}$ Timothy A. Pritts ${ }^{a}$ \\ aDepartment of Surgery and Institute for Military Medicine, University of Cincinnati, Cincinnati, USA; \\ ${ }^{b}$ Department of Molecular Biology, University of Duisburg-Essen, Essen, Germany
}

\section{Key Words}

Sphingomyelinase $\bullet$ Blood banking $\bullet$ Storage lesion $•$ Hemolysis

\begin{abstract}
Background/Aims: During storage, units of human red blood cells ( $p R B C s$ ) experience membrane destabilization and hemolysis which may cause harm to transfusion recipients. This study investigates whether inhibition of acid sphingomyelinase could stabilize erythrocyte membranes and prevent hemolysis during storage. Methods: Human and murine pRBCs were stored under standard blood banking conditions with and without the addition of amitriptyline, a known acid sphingomyelinase inhibitor. Hemoglobin was measured with an electronic hematology analyzer and flow cytometry was used to measure erythrocyte size, complexity, phosphatidylserine externalization, and band 3 protein expression. Results: Cell-free hemoglobin, a marker of hemolysis, increased during PRBC storage. Amitriptyline treatment decreased hemolysis in a dose-dependent manner. Standard pRBC storage led to loss of erythrocyte size and membrane complexity, increased phosphatidylserine externalization, and decreased band 3 protein integrity as determined by flow cytometry. Each of these changes was reduced by treatment with amitriptyline. Transfusion of amitriptylinetreated pRBCs resulted in decreased circulating free hemoglobin. Conclusion: Erythrocyte storage is associated with changes in cell size, complexity, membrane molecular composition, and increased hemolysis. Acid sphingomyelinase inhibition reduced these changes in a dosedependent manner. Our data suggest a novel mechanism to attenuate the harmful effects after transfusion of aged blood products.
\end{abstract}

\section{Introduction}

The transfusion of human blood products, including stored red blood cell units (pRBCs), is necessary for the treatment of hemorrhage and anemia [1-4]. Compared to fresh units, transfusion of aged pRBCs has been associated with increased rates of pneumonia, sepsis, multi-organ failure, and mortality [5-8]. The presumed cause of these adverse outcomes 


\section{Cellular Physiology Cell Physiol Biochem 2016;39:331-340

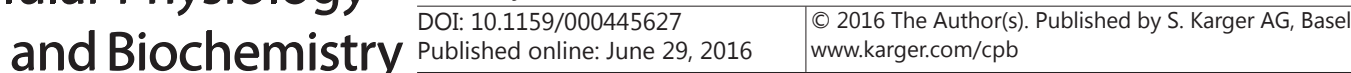 \\ Hoehn et al.: Acid Sphingomyelinase and Hemolysis}

is the erythrocyte "storage lesion", which is composed of a vast array of morphological and biochemical changes that occur as erythrocytes age during storage [9]. A particularly deleterious aspect of this lesion is the age-related hemolysis that occurs as erythrocyte structure degrades over time.

During pRBC storage, erythrocyte structural proteins, lipids, and carbohydrates undergo oxidative injury [10] which leads to alterations in membrane structural components [11]. Tyrosine phosphorylation of band 3 protein leads to cross-linking and diffusion from the erythrocyte membrane $[12,13]$. Phosphatidylserine becomes externalized, and erythrocytes lose membrane domain as well as their classic biconcave disc shape and deformability $[10,12,14]$. This increased fragility contributes to age-related acidosis and hemolysis as intracellular ions and molecules escape from the cells $[15,16]$.

Sphingolipids are a class of lipids with a backbone of sphingoid bases, and are known to play an important role in the regulation of cell membrane structure and integrity, cell signaling (in particular, cell stress) and apoptosis [17-21]. Ceramide, a sphingolipid created by the enzyme acid sphingomyelinase (ASM), is known to form microdomains on erythrocyte membranes [22] and has been strongly linked to eryptosis, or suicidal erythrocyte death [23-26]. Our research has recently shown treatment of pRBCs with amitriptyline prior to storage leads to reduced ASM activity, reduced ceramide concentrations, and decreased lung injury in mice receiving blood transfusions [27], but the associated mechanisms are not fully understood. In the present study, we hypothesized that inhibition of ASM during pRBC storage would reduce storage-related erythrocyte hemolysis.

\section{Materials and Methods}

\section{Animal Model}

Male C57BL/6 mice aged 8-10 weeks were purchased from Jackson Laboratories, fed standard laboratory diet and water ad libitum, and acclimated for 1 week in climate-controlled conditions with 12 hours light-dark cycles prior to use. All experiments were approved by the Institutional Animal Care and Use Committee at the University of Cincinnati.

\section{Blood Banking and Treatment}

Human pRBCs were purchased from Hoxworth Blood Bank (Cincinnati, OH) and stored at $4^{\circ} \mathrm{C}$ for 42 days according to standard blood banking practice [28]. These units were leukoreduced by filtration prior to storage as a matter of routine. Murine pRBCs were prepared and stored as previously described [29], and then stored in Eppendorf tubes as $1 \mathrm{~mL}$ "units" at $4^{\circ} \mathrm{C}$ for 14 days. These murine pRBCs were not routinely leukoreduced prior to storage. Where used, amitriptyline and fluoxetine (Sigma-Aldrich, St Louis, MO, USA) were dissolved in normal saline ( $0.9 \%$ sodium chloride) and added to mouse and human pRBCs in a 1:10 dilution prior to storage. Except for dose-response experiments, amitriptyline treatment refers to a $125 \mu \mathrm{M}$ concentration of amitriptyline in pRBCs. In this manuscript, "aged" refers to 42 days for human pRBCs and 14 days for murine pRBCs.

Our laboratory has an established murine blood banking model that is used for the in vitro study of erythrocyte storage as well as in vivo transfusion studies of various blood components [3, 29-31]. Due to this experience, the majority of experiments are performed with murine blood rather than human blood. In this study we will demonstrate an effect of ASM inhibition on hemolysis in both human and murine blood and further studies regarding the mechanism of this phenomenon, as well as in vivo transfusion, will be performed with murine blood alone.

\section{Blood Component Isolation}

Erythrocytes were pelleted from pRBC samples at $2,000 \mathrm{~g}$ for 10 minutes at $4^{\circ} \mathrm{C}$. The supernatant from this spin was then centrifuged at $10,000 \mathrm{~g}$ for 10 minutes at $4^{\circ} \mathrm{C}$ to pellet any remaining cells or platelets. Hemoglobin-containing microparticles were pelleted using a $20,000 \mathrm{~g}$ spin for 30 minutes at $4^{\circ} \mathrm{C}$ [32]. This final cell- and particle-free serum was used to analyze free hemoglobin, a marker of hemolysis. 


\section{Cellular Physiology Cell Physiol Biochem 2016;39:331-340 \begin{tabular}{l|l} 
and Biochemistry Published online: June 29, 2016 & $\begin{array}{l}\text { C } 2016 \text { The Author(s). Published by S. Karger AG, Basel } \\
\text { www.karger.com/cpb }\end{array}$
\end{tabular} \\ Hoehn et al.: Acid Sphingomyelinase and Hemolysis}

Erythrocyte Characterization

Cell-free hemoglobin was quantified using a Coulter AcT diff Analyzer (Beckman Coulter Corp., Brea, CA). We chose flow cytometry over microscopy to characterize changes to the erythrocyte membrane, as this method requires little manipulation prior to analysis of the cell. While microscopy offers more detailed imaging of the cell membrane, normal blood smears change the membrane shape and require fixation of cells that artificially distorts the membrane. On flow cytometry, erythrocytes were identified using antibodies to glyophorin A: murine cells with PE-conjugated ter-119 [33] and human cells with PE-conjugated CD235a [34]. Forward scatter (FSC) was used as a surrogate to measure erythrocyte size or volume, and side scatter (SSC) was used to estimate membrane complexity or roughness. Phosphatidylserine exposure (FITCconjugated annexin $\mathrm{V}$ [35]), and band 3 protein integrity (eosin-5-maleimide[36]) were analyzed using an Attune flow cytometer (Life Technologies, Carlsbad, CA). Antibodies for ter-119, CD235a, and Annexin $\mathrm{V}$ were acquired from BD Biosciences (San Diego, CA), and eosin-5-maleimide was obtained from Life Technologies (Carlsbad, CA).

\section{Effect on Transfusion Recipient}

Aged murine pRBCs (after 14 days of storage), with or without amitriptyline treatment, were transfused into healthy recipient mice to study the difference in free hemoglobin in the transfusion recipient. $500 \mu \mathrm{L}$ pRBC was injected via penile vein using a 25 gauge needle under isoflurane anesthesia. 30 minutes after transfusion, recipients were sacrificed and their circulating blood was collected via cardiac puncture. Cells were removed similar to the blood banking process and hemoglobin content was measured in the cell-free serum as above.

\section{Statistical Analysis}

Sample numbers from each experiment are reported in the figure legends. Figures represent mean values and error bars represent standard deviation. One-way ANOVA with post-hoc testing was used to compare means across more than 2 groups and t-tests were used to compare means between two groups. Significance was defined as p-value less than 0.05. All analysis was performed using SigmaPlot (Systat Software, San Jose, CA).

\section{Results}

Acid Sphingomyelinase Inhibition Reduces Age-Related Hemolysis

As hemolysis represents a significant component of the erythrocyte storage lesion, we initially determined the effect of ASM inhibition on hemolysis during pRBC storage. Human (Fig. 1A) and murine (Fig. 1B) pRBCs were treated with increasing doses of amitriptyline, a known ASM inhibitor [37], and we observed a dose-dependent reduction in hemolysis with treatment. Human pRBCs demonstrated the greatest reduction at 50-100 $\mu \mathrm{M}$. Murine pRBCs demonstrated the greatest effect at $125-250 \mu \mathrm{M}$ amitriptyline.

In order to determine the time course of free hemoglobin release during erythrocyte storage, we examined murine pRBCs throughout the planned storage period. Our data indicate that pRBC hemolysis tends to occur late during storage, at days 12 and 14 (Fig. 1C). Free hemoglobin release was significantly decreased with amitriptyline treatment at these time points as well (Fig. 1C).

Next, to verify that the reduction in hemolysis that we observed was due to ASM inhibition and not specific to amitriptyline, we treated murine pRBCs with fluoxetine, another functional inhibitor of ASM [37]. Fluoxetine treatment resulted in a significant reduction in hemolysis during pRBC storage (Fig. 1D). These data suggest that acid sphingomyelinase inhibition results in a dose-dependent reduction in hemolysis during pRBC storage.

Acid Sphingomyelinase Inhibition Stabilizes Erythrocyte Membranes during Storage

One potential mechanism for decreased erythrocyte hemolysis secondary to amitriptyline treatment is improved stabilization of the cell membrane. In order to examine the effect of amitriptyline treatment on characteristics of the red blood cell membrane, 

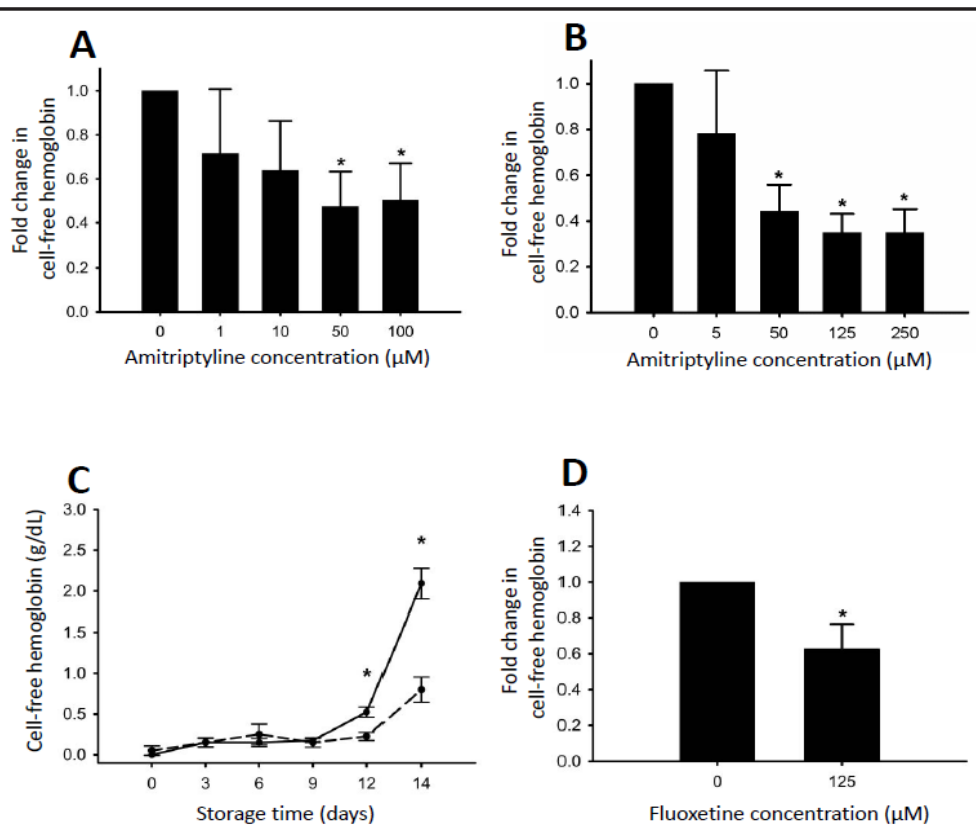

Fig. 1. Inhibition of acid sphingomyelinase reduces hemolysis in stored blood. Amitriptyline treatment dose-dependently reduces hemolysis in stored units of (A) human and (B) murine pRBCs (0 $\mu \mathrm{M}$ represents normal saline vehicle only, values represent fold change in cell-free hemoglobin at the end of storage, mean $\pm \mathrm{SD}, \mathrm{n}=5-7,{ }^{*} P<0.05$ vs $0 \mu \mathrm{M}$, ANOVA). (C) Amitriptyline treatment reduces hemolysis that occurs towards the end of murine pRBC storage (solid line = vehicle, dashed line $=125 \mu \mathrm{M}$ amitriptyline, ${ }^{*} P<0.05$ vs amitriptyline, t-test). (D) Fluoxetine treatment also reduced hemolysis in murine pRBCs during storage (mean $\pm \mathrm{SD}, \mathrm{n}=5,{ }^{*} P<0.01$ vs $0 \mu \mathrm{M}$, t-test).

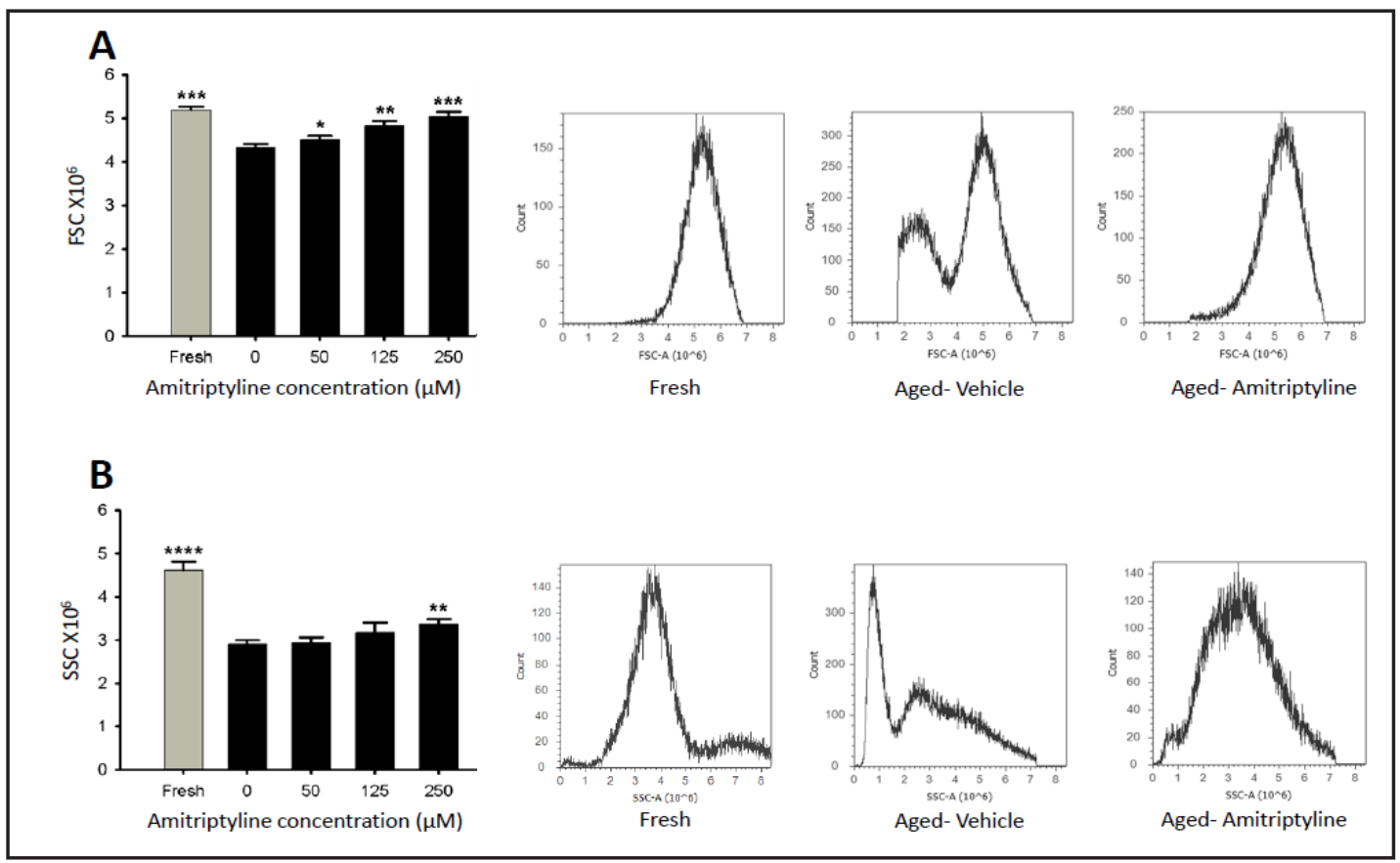

Fig. 2. Inhibition of acid sphingomyelinase prevents age related changes of mouse erythrocytes after 14 days of storage. Erythrocytes (ter-119 positive events) in aged, vehicle-treated pRBCs $(0 \mu \mathrm{M})$ demonstrate decreased size and complexity on flow cytometry, as indicated by forward scatter (A) and side scatter (B), respectively. Amitriptyline treatment dose-dependently prevented these changes (mean $\pm \mathrm{SD}, \mathrm{n}=5$, * $P<$ 0.05 vs $0 \mu \mathrm{M},{ }^{* *} P<0.05$ vs $0,50 \mu \mathrm{M}$, *** $P<0.05$ vs $0,50,125 \mu \mathrm{M}$, ${ }^{* * * *} P<0.05$ vs $\left.0,50,125,250 \mu \mathrm{M}\right)$.

\section{KARGER}




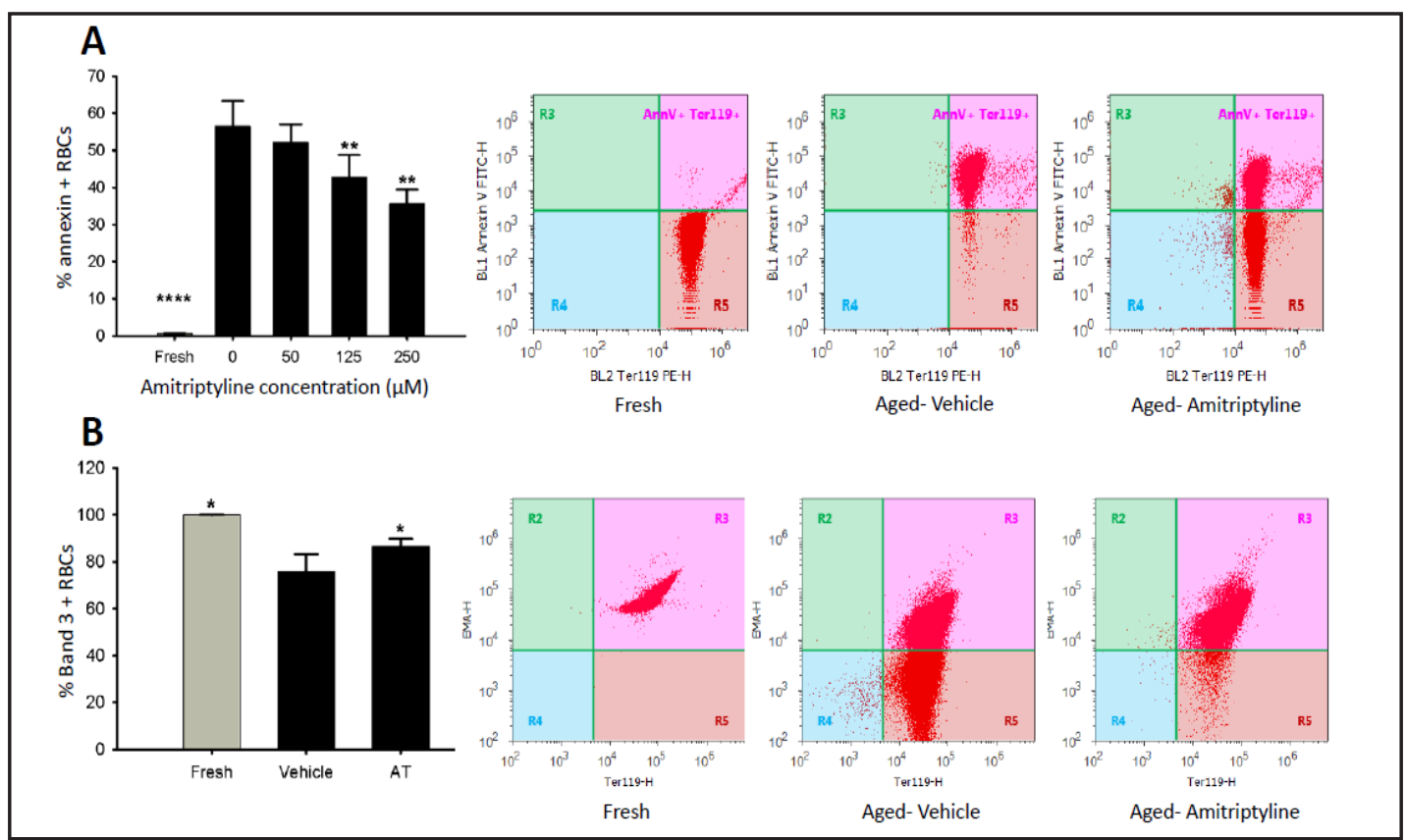

Fig. 3. Inhibition of acid sphingomyelinase prevents the age-related membrane structural changes. (A) Amitriptyline treatment reduces phosphatidylserine externalization. Fresh erythrocytes (ter-119 positive events) demonstrate almost no annexin V positivity, whereas aged vehicle-treated $(0 \mu \mathrm{M})$ show greatly increased positivity. Amitriptyline treatment dose-dependently reduced annexin $\mathrm{V}$ positivity (mean $\pm \mathrm{SD}, \mathrm{n}=$ 5 , ${ }^{*} P<0.05$ vs $0 \mu \mathrm{M},{ }^{* *} P<0.05$ vs $0,50 \mu \mathrm{M}$, ${ }^{* * * *} P<0.05$ vs $0,50,125,250 \mu \mathrm{M}$ ). (B) Acid sphingomyelinase inhibition preserves band 3 protein integrity. Erythrocytes were assayed on flow cytometry for band 3 protein, as measured by eosin-5-maleimide (EMA) positivity. Vehicle-treated aged pRBCs have decreased band 3 protein compared to fresh pRBCs, whereas amitriptyline (AT, $125 \mu \mathrm{M})$ treatment preserves band 3 protein (mean $\pm \mathrm{SD}, \mathrm{n}=5,{ }^{*} P<0.05$ vs vehicle).

we evaluated these characteristics by flow cytometry. Compared to freshly obtained erythrocytes, aged erythrocytes treated with vehicle (normal saline) demonstrate decreased size and membrane roughness compared to fresh erythrocytes (Fig. 2A and B). Storage of pRBCs with amitriptyline resulted in a dose-dependent preservation of size and roughness, suggesting that ASM inhibition results in membrane stabilization (Fig. 2A and B).

Phosphatidylserine, normally located on the intracellular plasma membrane, is known to become exteriorized during erythrocyte aging and serve as an indicator of senescence [10]. In order to examine the effect of ASM inhibition phosphatidylserine expression, murine pRBCs were stored with or without amitriptyline, labelled with FITC-coupled annexin V, and analyzed by flow cytometry. Phosphatidylserine externalization was nearly undetectable in fresh erythrocytes and sharply increased during pRBC storage (Fig. 3A). Storage of pRBCs with amitriptyline resulted in a dose-dependent reduction in phosphatidylserine externalization (Fig. 3A).

Another well-known aspect of the erythrocyte membrane disruption is altered expression of the key structural protein Band 3 [12]. Flow cytometry analysis demonstrated that a very high proportion of fresh erythrocytes express Band 3 protein, whereas expression is decreased during pRBC storage (Fig. 3B). Storage of pRBCs with amitriptyline reduced Band 3 protein loss by nearly $50 \%$. In summary, these findings suggest that ASM activity in stored pRBCs contributes to changes in erythrocyte size, complexity, and membrane composition, and that inhibition of ASM reduces these age-related changes.

Transfusion of Amitriptyline-Treated pRBCs Reduces Circulating Free Hemoglobin

After determining that acid sphingomyelinase inhibition prevented hemolysis during pRBC storage, we utilized a murine model of blood transfusion to study the effect on 
Fig. 4. Acid sphingomyelinase inhibition during pRBC storage reduces circulating free hemoglobin burden in transfusion recipients. Mice that received at $500 \mu \mathrm{L}$ transfusion of pRBCs stored with amitriptyline for 14 days (AT, $125 \mu \mathrm{M}$ ) demonstrated lower levels of circulating free hemoglobin than mice receiving vehicle-treated $\mathrm{pRBCs}$ (mean $\pm \mathrm{SD}, \mathrm{n}=4{ }^{*} P<$ 0.05 vs vehicle).

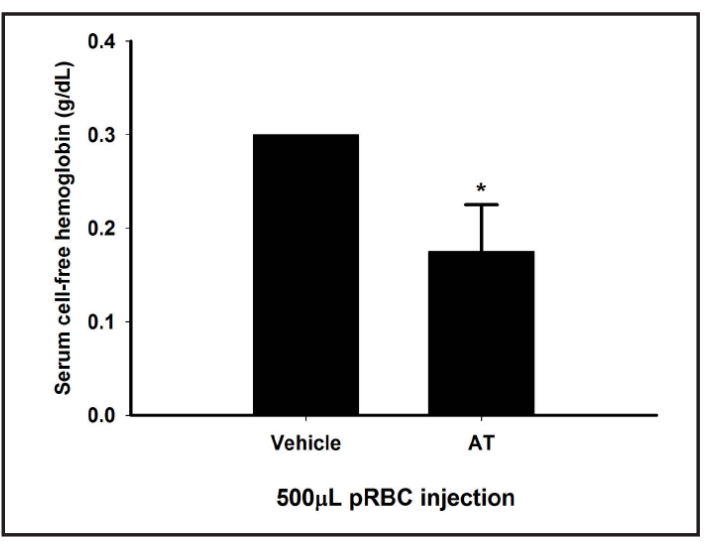

transfusion recipients. Mice received a $500 \mu \mathrm{L}$ transfusion of either vehicle- or amitriptylinetreated pRBCs after 14 days of storage. Following transfusion, mice receiving pRBCs treated with amitriptyline had significantly less circulating cell-free hemoglobin than mice receiving vehicle-treated pRBCs (Fig. 4). These data suggest that acid sphingomyelinase inhibition during $\mathrm{pRBC}$ storage benefits the transfusion recipient by decreasing the burden of free hemoglobin associated with transfusion of aged blood products.

\section{Discussion}

Our data demonstrate that hemolysis occurs in an age-related fashion during pRBC storage. Inhibition of ASM with amitriptyline results in a dose-dependent reduction in hemolysis in both human and murine pRBCs. Amitriptyline treatment also prevents changes in erythrocyte size and membrane roughness that occur during pRBC storage. Moreover, amitriptyline prevents phosphatidylserine externalization and loss of band 3 protein, two important aspects of the erythrocyte storage lesion. Subsequently, mice transfused amitriptyline-treated pRBCs received a significantly lower burden of free hemoglobin.

Cell-free hemoglobin in transfused pRBCs has been linked with adverse patient outcomes. Not only does free hemoglobin contribute to acute inflammation [38], it also scavenges nitric oxide, which is created by endothelial cells and helps control blood flow by inducing relaxation of vascular smooth muscle $[39,40]$. This limits endothelial-dependent vasodilation and end organ perfusion [15, 41-43], which has been suggested to adversely affect clinical outcomes [38, 44-48]. Moreover, patients with cancer and other chronic conditions necessitating frequent blood transfusions can demonstrate iron overload and subsequent organ dysfunction over time [49]. As one pRBC contains 220-250mg of iron, transfusion recipients must clear greater than $50 \mathrm{mg}$ of iron per pRBC transfused [50]. The ability to reduce this burden of free hemoglobin, as seen in our murine model of blood transfusion, may offer a great opportunity to reduce some of the deleterious consequences of aged pRBC transfusion.

The erythrocyte storage lesion is a broad collection of biochemical and morphological changes that occur as these cells age during pRBC storage. Most of these changes, such as increased lactate and potassium concentrations, are merely descriptive and do not identify mechanisms of erythrocyte breakdown. It was posited that oxidative stress leads to morphological alterations of key structural proteins and lipids such as band 3 protein and phosphatidylserine [10-12]. Indeed, treatment of erythrocytes with natural antioxidants has been shown to prolong survival and reduce phosphatidylserine exposure [51]. Dinkla et al. [22] have recently shown that incubation of erythrocytes with sphingomyelinase results in the formation of ceramide-enriched platforms, phosphatidylserine exposure, band 3 changes, and CD59 clustering, and that these changes lead to decreased cell size and increased cell fragility. We have shown that inhibition of ASM during pRBC storage prevents 
these changes, further implicating sphingolipid metabolism as a driver of many important aspects of the erythrocyte storage lesion, including hemolysis. Multiple studies have shown similar findings; treatment of stored blood with a variety of compounds has led to ceramide formation with increased membrane reorganization and eryptosis in vitro [52-58].

ASM has been previously implied in the formation and release of microparticles from erythrocytes $[31,59]$. Thus, it is important to know whether the measured "cell-free hemoglobin" is microparticle bound versus actually suspended in serum [60]. In order to distinguish the two, we performed multiple centrifugation to identify the fraction containing hemoglobin. Erythrocytes were pelleted first, followed by leukocytes and then platelets. Next, the microparticle-rich supernatant was centrifuged at 20,000 $g$ for 30 minutes in order to remove microparticles [32]. This microparticle-poor supernatant was used to quantify free hemoglobin as a marker of hemolysis. It is possible that this serum still contained hemoglobin in smaller particles such as exosomes. However, even after centrifugation of up to $100,000 \mathrm{~g}$ for 60 minutes there was still a visible difference in free hemoglobin between units that were and were not treated with amitriptyline (unpublished observations). As such, the authors feel confident that ASM inhibition results in not only reduced microparticle production [31] but also a decrease in the release of free hemoglobin.

The age-related derangements in erythrocyte structure we observed, specifically phosphatidylserine and band 3 protein, are known to contribute to adverse erythrocyte survival after pRBC transfusion [10,61]. Not only does storage result in erythrocytes that are less deformable and less able to pass through capillaries, the externalization of phosphatidylserine contributes to endothelial cell adhesion that may contribute to microangiopathy and tissue damage $[62,63]$. The role of ASM in these age-related changes is incompletely understood. However, our data indicate that amitriptyline treatment maintains erythrocyte structural integrity by preserving band 3 protein as well as the internalization of phosphatidylserine. While we cannot describe the absolute effect on band 3 concentration, the structure of the protein is preserved with amitriptyline based on the immunoreactivity in our assay. This may potentially explain the decreased hemolysis we observed. These findings provide evidence linking ASM activity in stored erythrocytes with membrane degradation over time.

One concern with the use of amitriptyline as a pRBC additive may be the potential toxicity of transfusing large volumes of pRBCs treated with amitriptyline. Reported toxicity of amitriptyline in animals ranges from $15-30 \mathrm{mg} / \mathrm{kg}[64,65]$. If amitriptyline remained stable during pRBC storage, which is unlikely, this would mean that a $70 \mathrm{~kg}$ patient would receive a toxic dose of amitriptyline at doses around $1 \mathrm{~g}$. This equates to $25.5 \mathrm{~L}$ of blood, or $>100$ pRBC bags, treated with $125 \mu \mathrm{M}$ amitriptyline. A patient receiving this volume would likely be actively bleeding, thus losing amitriptyline at the same time it is being transfused and unable to accumulate a toxic dose of the drug. While the potential toxicity of this therapy seems improbable, our lab plans to investigate the pharmacokinetics of amitriptyline in stored pRBCs before taking this therapy to the clinical arena.

In conclusion, we have shown that ASM activity during pRBC storage correlates with known aspects of the erythrocyte storage lesion. Treatment with amitriptyline, an FDAapproved inhibitor of ASM [66], dramatically reduced hemolysis during pRBC storage. Further, we have found that ASM inhibition correlates with preservation of phosphatidylserine and band 3 protein integrity, suggesting a possible mechanism by which ASM activity may contribute to age-related erythrocyte degradation. Combined with recent work from our lab [31], these findings further indicate that sphingolipid metabolism, specifically ASM activity, is a novel target for improving the quality of stored blood products.

\section{Acknowledgements}

This study was supported in part by grant R01 GM107625 from the National Institute of General Medical Sciences of the US National Institutes of Health and DFG grant GU 335/30-1. 


\section{Cellular Physiology Cell Physiol Biochem 2016;39:331-340 \begin{tabular}{l|l} 
DOI: 10.1159/000445627 & and Biochemistry \\
Published online: June 29, 2016 & $\begin{array}{l}\text { O 2016 The Author(s). Published by S. Karger AG, Basel } \\
\text { www.karger.com/cpb }\end{array}$
\end{tabular} \\ Hoehn et al.: Acid Sphingomyelinase and Hemolysis}

\section{Disclosure Statement}

The authors report no conflicts of interest.

\section{References}

1 Schorn MN, Phillippi JC: Volume replacement following severe postpartum hemorrhage. J Midwifery Womens Health 2014;59:336-343.

2 Holcomb JB, Pati S: Optimal trauma resuscitation with plasma as the primary resuscitative fluid: The surgeon's perspective. Hematology Am Soc Hematol Educ Program 2013;2013:656-659.

3 Makley AT, Goodman MD, Friend LA, Deters JS, Johannigman JA, Dorlac WC, Lentsch AB, Pritts TA: Resuscitation with fresh whole blood ameliorates the inflammatory response after hemorrhagic shock. J Trauma 2010;68:305-311.

4 Holcomb JB, Jenkins D, Rhee P, Johannigman J, Mahoney P, Mehta S, Cox ED, Gehrke MJ, Beilman GJ, Schreiber M, Flaherty SF, Grathwohl KW, Spinella PC, Perkins JG, Beekley AC, McMullin NR, Park MS, Gonzalez EA, Wade CE, Dubick MA, Schwab CW, Moore FA, Champion HR, Hoyt DB, Hess JR: Damage control resuscitation: Directly addressing the early coagulopathy of trauma. J Trauma 2007;62:307-310.

5 Koch CG, Li L, Sessler DI, Figueroa P, Hoeltge GA, Mihaljevic T, Blackstone EH: Duration of red-cell storage and complications after cardiac surgery. N Engl J Med 2008;358:1229-1239.

6 Weinberg JA, McGwin G, Marques MB, Cherry SA, Reiff DA, Kerby JD, Rue LW: Transfusions in the less severely injured: Does age of transfused blood affect outcomes? J Trauma 2008;65:794-798.

7 Offner PJ, Moore EE, Biffl WL, Johnson JL, Silliman CC: Increased rate of infection associated with transfusion of old blood after severe injury. Arch Surg 2002;137:711-716; discussion 716-717.

8 Zallen G, Offner PJ, Moore EE, Blackwell J, Ciesla DJ, Gabriel J, Denny C, Silliman CC: Age of transfused blood is an independent risk factor for postinjury multiple organ failure. Am J Surg 1999;178:570-572.

9 Koch CG, Figueroa PI, Li L, Sabik JF, Mihaljevic T, Blackstone EH: Red blood cell storage: How long is too long? Ann Thorac Surg 2013;96:1894-1899.

10 Hess JR: Red cell changes during storage. Transfus Apher Sci 2010;43:51-59.

11 Kriebardis AG, Antonelou MH, Stamoulis KE, Economou-Petersen E, Margaritis LH, Papassideri IS: Storagedependent remodeling of the red blood cell membrane is associated with increased immunoglobulin $\mathrm{g}$ binding, lipid raft rearrangement, and caspase activation. Transfusion 2007;47:1212-1220.

12 Karon BS, Hoyer JD, Stubbs JR, Thomas DD: Changes in band 3 oligomeric state precede cell membrane phospholipid loss during blood bank storage of red blood cells. Transfusion 2009;49:1435-1442.

13 Ferru E, Giger K, Pantaleo A, Campanella E, Grey J, Ritchie K, Vono R, Turrini F, Low PS: Regulation of membrane-cytoskeletal interactions by tyrosine phosphorylation of erythrocyte band 3. Blood 2011;117:5998-6006.

14 Izzo P, Manicone A, Spagnuolo A, Lauta VM, Di Pasquale A, Di Monte D: Erythrocytes stored in cpd sagmannitol: Evaluation of their deformability. Clin Hemorheol Microcirc 1999;21:335-339.

15 Bennett-Guerrero E, Veldman TH, Doctor A, Telen MJ, Ortel TL, Reid TS, Mulherin MA, Zhu H, Buck RD, Califf RM, McMahon TJ: Evolution of adverse changes in stored rbcs. Proc Natl Acad Sci USA 2007;104:1706317068.

16 Berezina TL, Zaets SB, Morgan C, Spillert CR, Kamiyama M, Spolarics Z, Deitch EA, Machiedo GW: Influence of storage on red blood cell rheological properties. J Surg Res 2002;102:6-12.

17 Gulbins E: Regulation of death receptor signaling and apoptosis by ceramide. Pharmacol Res 2003;47:393399.

18 Gulbins E, Kolesnick R: Acid sphingomyelinase-derived ceramide signaling in apoptosis. Subcell Biochem 2002;36:229-244.

19 Tirodkar TS, Voelkel-Johnson C: Sphingolipids in apoptosis. Exp Oncol 2012;34:231-242.

20 Aguilera-Romero A, Gehin C, Riezman H: Sphingolipid homeostasis in the web of metabolic routes. Biochim Biophys Acta 2014;1841:647-656.

21 Grassmé H, Riethmüller J, Gulbins E: Biological aspects of ceramide-enriched membrane domains. Prog Lipid Res 2007;46:161-170. 


\section{Cellular Physiology Cell Physiol Biochem 2016;39:331-340 \begin{tabular}{l|l|} 
and Biochemistry 10.1159/000445627 & $\begin{array}{l}\text { C) 2016 The Author(s). Published by S. Karger AG, Basel } \\
\text { www.karger.com/cpb }\end{array}$
\end{tabular} \\ Hoehn et al.: Acid Sphingomyelinase and Hemolysis}

22 Dinkla S, Wessels K, Verdurmen WP, Tomelleri C, Cluitmans JC, Fransen J, Fuchs B, Schiller J, Joosten I, Brock R, Bosman GJ: Functional consequences of sphingomyelinase-induced changes in erythrocyte membrane structure. Cell Death Dis 2012;3:e410.

23 Lang E, Bissinger R, Gulbins E, Lang F: Ceramide in the regulation of eryptosis, the suicidal erythrocyte death. Apoptosis 2015;20:758-767.

24 Lang F, Gulbins E, Lang PA, Zappulla D, Föller M: Ceramide in suicidal death of erythrocytes. Cell Physiol Biochem 2010;26:21-28.

25 Bouguerra G, Bissinger R, Abbès S, Lang F: Stimulation of eryptosis by narasin. Cell Physiol Biochem 2015;37:1807-1816.

26 Stockinger K, Bissinger R, Bouguerra G, Abbès S, Lang F: Enhanced eryptosis following exposure to carnosic acid. Cell Physiol Biochem 2015;37:1779-1791.

27 Hoehn RS, Jernigan PL, Japtok L, Chang AL, Midura EF, Caldwell CC, Kleuser B, Lentsch AB, Edwards MJ, Gulbins E, Pritts TA: Acid sphingomyelinase inhibition in stored erythrocytes reduces transfusionassociated lung inflammation. Ann Surg DOI:10.1097/SLA.0000000000001648.

28 Wehrli G: Blood banking and transfusion medicine for the nephrologist. Semin Dial 2012;25:114-118.

29 Belizaire RM, Prakash PS, Richter JR, Robinson BR, Edwards MJ, Caldwell CC, Lentsch AB, Pritts TA: Microparticles from stored red blood cells activate neutrophils and cause lung injury after hemorrhage and resuscitation. J Am Coll Surg 2012;214:648-655; discussion 656-647.

30 Belizaire RM, Makley AT, Campion EM, Sonnier DI, Goodman MD, Dorlac WC, Friend LA, Lentsch AB, Pritts TA: Resuscitation with washed aged packed red blood cell units decreases the proinflammatory response in mice after hemorrhage. J Trauma Acute Care Surg 2012;73:S128-133.

31 Hoehn RS, Jernigan PL, Japtok L, Chang AL, Midura EF, Caldwell CC, Kleuser B, Lentsch AB, Edwards MJ, Gulbins E, Pritts TA: Acid sphingomyelinase inhibition in stored erythrocytes reduces transfusionassociated lung inflammation. Ann Surg 2016

32 György B, Szabó TG, Pásztói M, Pál Z, Misják P, Aradi B, László V, Pállinger E, Pap E, Kittel A, Nagy G, Falus A, Buzás EI: Membrane vesicles, current state-of-the-art: Emerging role of extracellular vesicles. Cell Mol Life Sci 2011;68:2667-2688.

33 Kina T, Ikuta K, Takayama E, Wada K, Majumdar AS, Weissman IL, Katsura Y: The monoclonal antibody ter119 recognizes a molecule associated with glycophorin a and specifically marks the late stages of murine erythroid lineage. Br J Haematol 2000;109:280-287.

34 Nakahata T, Okumura N: Cell surface antigen expression in human erythroid progenitors: Erythroid and megakaryocytic markers. Leuk Lymphoma 1994;13:401-409.

35 Bissinger R, Al Mamun Bhuyan A, Signoretto E, Lang F: Stimulating effect of elvitegravir on suicidal erythrocyte death. Cell Physiol Biochem 2016;38:1111-1120.

36 King MJ, Behrens J, Rogers C, Flynn C, Greenwood D, Chambers K: Rapid flow cytometric test for the diagnosis of membrane cytoskeleton-associated haemolytic anaemia. Br J Haematol 2000;111:924-933.

37 Kornhuber J, Tripal P, Reichel M, Mühle C, Rhein C, Muehlbacher M, Groemer TW, Gulbins E: Functional inhibitors of acid sphingomyelinase (fiasmas): A novel pharmacological group of drugs with broad clinical applications. Cell Physiol Biochem 2010;26:9-20.

38 Hod EA, Zhang N, Sokol SA, Wojczyk BS, Francis RO, Ansaldi D, Francis KP, Della-Latta P, Whittier S, Sheth S, Hendrickson JE, Zimring JC, Brittenham GM, Spitalnik SL: Transfusion of red blood cells after prolonged storage produces harmful effects that are mediated by iron and inflammation. Blood 2010;115:4284-4292.

39 Walford G, Loscalzo J: Nitric oxide in vascular biology. J Thromb Haemost 2003;1:2112-2118.

40 Palmer RM, Ferrige AG, Moncada S: Nitric oxide release accounts for the biological activity of endotheliumderived relaxing factor. Nature 1987;327:524-526.

41 Neuman R, Hayek S, Rahman A, Poole JC, Menon V, Sher S, Newman JL, Karatela S, Polhemus D, Lefer DJ, De Staercke C, Hooper C, Quyyumi AA, Roback JD: Effects of storage-aged red blood cell transfusions on endothelial function in hospitalized patients. Transfusion 2014;55:782-790.

42 Reynolds JD, Ahearn GS, Angelo M, Zhang J, Cobb F, Stamler JS: S-nitrosohemoglobin deficiency: A mechanism for loss of physiological activity in banked blood. Proc Natl Acad Sci U S A 2007;104:1705817062.

43 Rigamonti A, McLaren AT, Mazer CD, Nix K, Ragoonanan T, Freedman J, Harrington A, Hare GM: Storage of strain-specific rat blood limits cerebral tissue oxygen delivery during acute fluid resuscitation. Br J Anaesth 2008;100:357-364. 


\section{Cellular Physiology Cell Physiol Biochem 2016;39:331-340

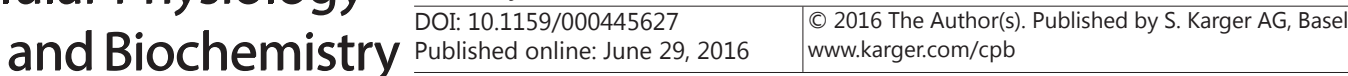 \\ Hoehn et al.: Acid Sphingomyelinase and Hemolysis}

44 Brown CH, Grega M, Selnes OA, McKhann GM, Shah AS, LaFlam A, Savage WJ, Frank SM, Hogue CW, Gottesman RF: Length of red cell unit storage and risk for delirium after cardiac surgery. Anesth Analg 2014;119:242-250.

45 Baek JH, D'Agnillo F, Vallelian F, Pereira CP, Williams MC, Jia Y, Schaer DJ, Buehler PW: Hemoglobin-driven pathophysiology is an in vivo consequence of the red blood cell storage lesion that can be attenuated in guinea pigs by haptoglobin therapy. J Clin Invest 2012;122:1444-1458.

46 Baron DM, Yu B, Lei C, Bagchi A, Beloiartsev A, Stowell CP, Steinbicker AU, Malhotra R, Bloch KD, Zapol WM: Pulmonary hypertension in lambs transfused with stored blood is prevented by breathing nitric oxide. Anesthesiology 2012;116:637-647.

47 Matot I, Katz M, Pappo O, Zelig O, Corchia N, Yedgar S, Barshtein G, Bennett-Guerrero E, Guerrero EB, Abramovitch R: Resuscitation with aged blood exacerbates liver injury in a hemorrhagic rat model. Crit Care Med 2013;41:842-849.

48 Hod EA, Brittenham GM, Billote GB, Francis RO, Ginzburg YZ, Hendrickson JE, Jhang J, Schwartz J, Sharma S, Sheth S, Sireci AN, Stephens HL, Stotler BA, Wojczyk BS, Zimring JC, Spitalnik SL: Transfusion of human volunteers with older, stored red blood cells produces extravascular hemolysis and circulating nontransferrin-bound iron. Blood 2011;118:6675-6682.

49 Ruccione KS, Wood JC, Sposto R, Malvar J, Chen C, Freyer DR: Characterization of transfusion-derived iron deposition in childhood cancer survivors. Cancer Epidemiol Biomarkers Prev 2014;23:1913-1919.

50 Ozment CP, Turi JL: Iron overload following red blood cell transfusion and its impact on disease severity. Biochim Biophys Acta 2009;1790:694-701.

51 Kucherenko YV, Bernhardt I: Natural antioxidants improve red blood cell "Survival" In non-leukoreduced blood samples. Cell Physiol Biochem 2015;35:2055-2068.

52 Bissinger R, Waibel S, Bouguerra G, Al Mamun Bhuyan A, Abbès S, Lang F: Enhanced eryptosis following exposure to lopinavir. Cell Physiol Biochem 2015;37:2486-2495.

53 Bouguerra G, Aljanadi O, Bissinger R, Abbès S, Lang F: Embelin-induced phosphatidylserine translocation in the erythrocyte cell membrane. Cell Physiol Biochem 2015;37:1629-1640.

54 Bouguerra G, Bissinger R, Abbès S, Lang F: Zopolrestat induced suicidal death of human erythrocytes. Cell Physiol Biochem 2015;37:1537-1546.

55 Faggio C, Alzoubi K, Calabrò S, Lang F: Stimulation of suicidal erythrocyte death by prima-1. Cell Physiol Biochem 2015;35:529-540.

56 Calabrò S, Alzoubi K, Faggio C, Laufer S, Lang F: Triggering of suicidal erythrocyte death following boswellic acid exposure. Cell Physiol Biochem 2015;37:131-142.

57 Zierle J, Bissinger R, Egler J, Lang F: Lapatinib induced suicidal death of human erythrocytes. Cell Physiol Biochem 2015;37:2275-2287.

58 Egler J, Lang F: Licochalcone a induced suicidal death of human erythrocytes. Cell Physiol Biochem 2015;37:2060-2070.

59 Awojoodu AO, Keegan PM, Lane AR, Zhang Y, Lynch KR, Platt MO, Botchwey EA: Acid sphingomyelinase is activated in sickle cell erythrocytes and contributes to inflammatory microparticle generation in scd. Blood 2014;124:1941-1950.

60 Greenwalt TJ, McGuinness CG, Dumaswala UJ: Studies in red blood cell preservation: 4. Plasma vesicle hemoglobin exceeds free hemoglobin. Vox Sang 1991;61:14-17.

61 Card RT: Red cell membrane changes during storage. Transfus Med Rev 1988;2:40-47.

62 Anniss AM, Sparrow RL: Storage duration and white blood cell content of red blood cell (rbc) products increases adhesion of stored rbcs to endothelium under flow conditions. Transfusion 2006;46:1561-1567.

63 Relevy H, Koshkaryev A, Manny N, Yedgar S, Barshtein G: Blood banking-induced alteration of red blood cell flow properties. Transfusion 2008;48:136-146.

64 Lheureux P, Vranckx M, Leduc D, Askenasi R: Flumazenil in mixed benzodiazepine/tricyclic antidepressant overdose: A placebo-controlled study in the dog. Am J Emerg Med 1992;10:184-188.

65 Hughes IE, Radman S: Relative toxicity of amitriptyline, imipramine, maprotiline and mianserin after intravenous infusion in conscious rabbits. Br J Clin Pharmacol 1978;5 Suppl 1:19S-20S.

66 Kornhuber J, Tripal P, Gulbins E, Muehlbacher M: Functional inhibitors of acid sphingomyelinase (fiasmas). Handb Exp Pharmacol 2013:169-186. 